\title{
A NOTE ON NAMES AND TERMS
}

Names are given in the Japanese order, surname first.

A word is in order concerning Makiko's somewhat capricious use of the words affixed to either the surname or the given name. These words are -san, -sama, -chan, -sensei, -don, -han, and -yan, and, being gender-blind, they pose something of a problem for the translator. None of these terms makes distinction as to marital status, including the Kyoto localisms - han and -yan. The term -chan, a diminutive of -san, is used almost exclusively for children of both sexes. Where it is important to know whether the individual is a boy or girl, I have given the information in a footnote. The term sensei, roughly equivalent to "teacher," is used for distinguished individuals and professionals. The term -don is used only for servants, male and female.

For the convenience of the reader of English, I have altered some of the names as they appear in the diary. For example, Makiko never referred to her brother by his name, "Manzō," but always as ani (elder brother). Similarly, she called her half-sister Senbon no neesan (elder sister who lives in Senbon), but for the sake of simplicity, I have used "Elder Sister Kōshima." Kinship usage in Japan forbids use of the first name alone for persons who occupy a status superior to the speaker, even if they are chronologically younger. The reason that Makiko refers to her brother-in-law Hidesaburō by his name even though he is two years older is that, as the wife of his elder brother, she outranks him in the household hierarchy.

Makiko sometimes uses the terms "uncle" (oji-san) and "aunt" (oba-san) in referring to older relatives, old family friends, and neigh- 
bors who are of her parents' generation. As in American English, these terms are used for non-kin to indicate a particular feeling of closeness and a degree of intimacy.

Makiko's style does have one interesting characteristic that probably reflects the usage of the time. She uses -sama, today considered more formal than -san, for some of her friends and other intimates, such as Matsui Jisuke, who marries her husband's sister. He is invariably referred to as Matsui-sama.

In giving recipes, Makiko uses the Japanese units of measure: I shō equals I.8 liters (or I.9 quarts); there are Io gō in I shō and Io shō in $\mathrm{I}$ to.

In I9Io the yen was equal to about $\$ 0.50$. There are 100 sen in I yen and Io rin in I sen. There are no reliable statistics for family income or average annual wage in 1910 , but $I$ have found figures for the average annual income of certain categories of worker at about this time. In 1907 a male certified primary school teacher's annual income was $¥ 260$; a female earned $¥$ I 80 . In 1910, a male farm laborer’s annual wages were $¥ 47$, and a female’s $¥ 28.50$, while male domestic servants earned $¥ 54.72$, and females $¥ 35.52$ (Tōyō Keizai Shinpōsha). In 1909 the annual wage of a female silk-reeler employed by a spinning company in Nagano prefecture was about $¥ 60$ (Tsurumi, p. 72). The only reference to an annual wage in Makiko's diary concerns her father's housekeeper, who was seeking an increase from $¥ 48$ to $¥ 50$. 
The Families of Nakano Chūhachi, Tanii, and the "Eastside" in 1910

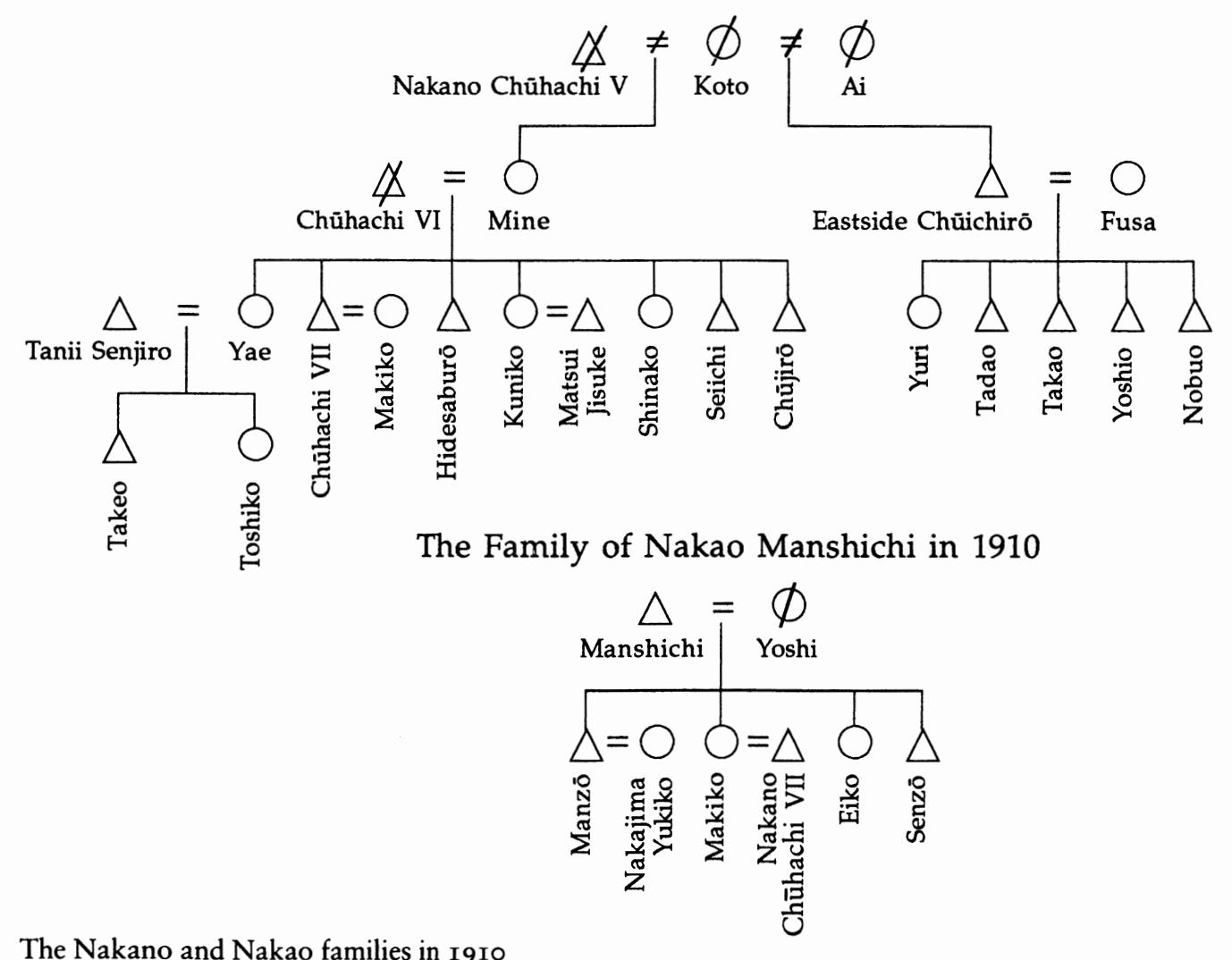

